\title{
Upgrade of Trade Structure Based on the Average Proximity
}

\author{
Mengli Wang ${ }^{1, a}$, Tieju $\mathrm{Ma}^{2, \mathrm{~b}}$ and Mengyu Qiao ${ }^{3, \mathrm{c}}$ \\ ${ }^{1}$ School of business, East China University of Science and Technology, Shanghai, China \\ ${ }^{2}$ School of business, East China University of Science and Technology, Shanghai, China \\ ${ }^{3}$ School of business, East China University of Science and Technology, Shanghai, China \\ awml665@163.com, btjma@ecust.edu.cn, 'ciaomengyu7353@163.com
}

\begin{abstract}
Keywords: Average proximity; Product space; Export trade structure; Revealed comparative advantage
\end{abstract}

Abstract. This article analyzed the relationship between average proximity and the amount of export trade of RCA $>1$ based on 1984-2010 international trade data. First, we introduced the concept of average proximity. Then we summarized product evolution law and showed all products evolution by product space. Finally, we provided empirical evidence of China based on 1984-2010 China export trade data. We find average proximity can explain variation of number of product with RCA $>1$ well. We also conclude that China export economy complexity is overestimated and China's exports will be still rising. This paper only considers what countries/areas export without import. We also don't take the relationship of competition and restriction between countries into consideration. Still, it is an important supplement for international trade and economy complexity field. It is significant for China to make feasible trade policies and achieve trade structure upgrade efficiently.

\section{Introduction}

The focused on export trade changes from the amount of export trade to economy complexity and product proximity gradually in recent years. Researchers both at home and abroad have long-term concern on the promoting of export trade to economic growth. Part studies mainly measure it by revealed comparative advantage index in the beginning, while recently many studies measure it in terms of export trade as a share of GDP, which only reflect the amount of export trade rather than the export products quality, technology and labor productivity, etc. In most cases, the inherent problems of export trade are not only a matter of exports but the technical content and complexity. Therefore, after entering 21 st century, researchers are focus on export trade gradually changes from the number of export trade to economy complexity and product proximity. To study a country exports' economic growth and the international competitiveness from the perspective of economy complexity and product proximity has more advantages than from the perspective of quantity.

Balassa(1965)[1] first proposes the revealed comparative advantage index, RCA index for short, which is an important concept in economic theory. It is to measure a country's product in the international competitiveness. Haussmann et al.(2005)[2] propose a method to measure economy complexity, which combines the revealed comparative advantage index with the income level of a country. Hidalgo et al.(2007)[3] define the proximity and density. The measure of two products proximity is based on the conditional probability of having revealed comparative advantage to show products highly or lowly connected. The higher proximity of other products nearby, the product is easier to transfer from undeveloped product to developed product[4].

As the products with high technology had faster growth rate than other products (Lall, 2000; Lee, 2011)[5,6], the exporters which export high technology products have more profitable and more advantage than other countries. For this purpose, the country should give export encouragement to high technological products and give appropriate restrictions to low technological products production and export, thus to raise their economy complexity[7].

Although calculating countries'/areas' economy complexity and products' proximity mentioned above have absorbing a lot of attentions of researchers as well as policy makers. There is no deep analysis on how many related products impact a product more appropriate. Based on the calculation, 
this paper analyzed how many related products impacting a product more appropriate and analyzes the relationship between average proximity and the amount of export trade of RCA $>1$ based on 1984-2010 international trade data.

\section{Method}

The method is put forward by Hidalgo et. al(2007)[3]. It is an agnostic approach and uses an outcomes-based measure, based on the idea that if two products are related, that is to say, they require similar quality, technology and labor productivity, etc. they will tend to be produced together, whereas highly different products are unlikely to be produced together.

Our measure of similarity between products $i$ and $j$ is based on the conditional probability of having Revealed Comparative Advantage, which measures whether a country is an effective exporter $(\mathrm{RCA}>1)$ of a given product $\mathrm{i}$ or not $(\mathrm{RCA}<1)$, given that the country has revealed comparative advantage in product $\mathrm{j}$ at time $\mathrm{t}$, and vice versa. Then the proximity is

$\varphi_{i, j, t}=\min \left\{P\left(R C A x_{i, t} \mid R C A x_{j, t}\right), P\left(R C A x_{j, t} \mid R C A x_{i, t}\right)\right\}$

Where products are indexed with $i$ and $j$ and years are indexed with $t$. RCAi,t and RCAj,t denote the export of product $i$ and the export of product $j$ ' Revealed Comparative Advantage index in year $t$. A product's Revealed Comparative Advantage index, the RCAj,t in Eq. 1, is calculated with Eq. 2.

$$
\operatorname{RCA}_{c, j, t}=\frac{v_{c, j, t} / \sum_{j=0}^{m} v_{c, j, t}}{\sum_{c=1}^{n} v_{c, j, t} / \sum_{c=1}^{n} \sum_{j=0}^{m} v_{c, j, t}}
$$

Where countries/areas are indexed with $\mathrm{c}$. Vc,i,j denotes the export of product $\mathrm{j}$ from country $\mathrm{c}$ in year $\mathrm{t}$.

Hidalgo et al.(2007) adopt a strongest relevant product namely the one with most proximity to analyze and simulate countries/region's product structure and upgrade. However we argue that using a combination of top several related products to analyze the product structure and upgrade will be more reasonable. Therefore the paper get improved based on Hidalgo et al. (2007) method, and introduce the concept of average proximity.

$\bar{\varphi}_{i, t}=\sum_{j=1}^{J} \varphi_{i, j, t}$

$\mathrm{J}$ is the best number of related products.

In the following, we use this method to calculate average proximity and analyze conversion probability distribution, and simulate evolution of the products with RCA $>1$.

\section{Data and Results}

\section{Data}

In this study, the international trade data are originally from United Nations Commodity Trade Statistics Database (COMTRADE), the same as Huasmman and Hidalgo's study on Economic Complexity(Huasmman and Hidalgo, 2013)[8] (http://atlas.media.mit.edu/). We use the international trade data from 1984 to 2010, classified with the 4-digit level of Standard International Trade Classification (revision 2). There are 241 countries/regions and 781 products totally in the world. The countries/areas in the trade data are different in different year. Some countries divided into several, for example, the former Soviet Union. Some countries merged together, for example, the East Germany and the West Germany. 


\section{Results}

With the data introduced above, we calculated all products' average proximity, and found a product with a combination of top three related products have appropriate analysis results. As a result, we used the top three relevant products to calculate average proximity, so $\mathrm{J}=3$.

Considering the conversion probability of every year is lower and transformation law is not obvious, we calculated conversion probability of every 5 years to make the law show more clear.

We considered that an export product with an RCA less than 0.5 in 1984. If the same product's RCA $>1$ in 1989, then it is transition product, otherwise it is undeveloped product, disregarding the rest as inconclusive. We computed the 22 group conversion probability from 1984-1989 to 2005-2010, and sought average conversion probability distribution. Fig. 1 shows a monotonic relationship between average proximity of the three nearest products and the average conversion probability. While the probability of moving into a product at average proximity 0.1 in the course of 5 years is very small, the probability is about 30 percent if the three closest products are at average proximity of 0.9 。

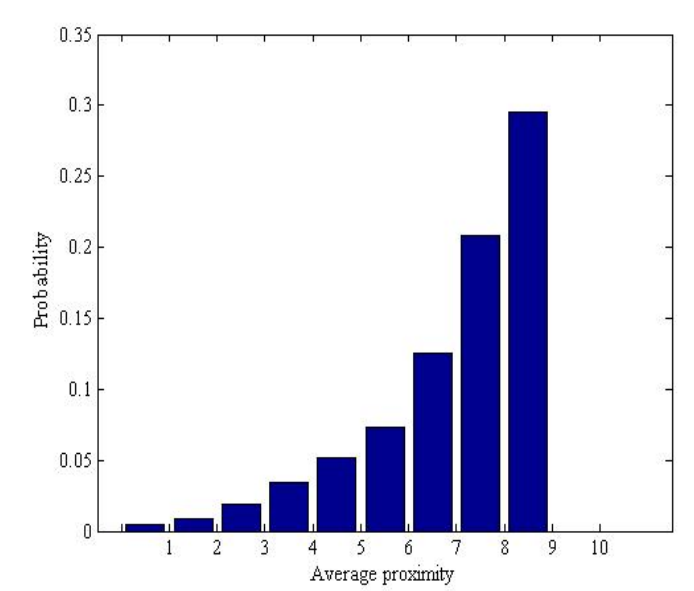

Fig. 1. Average conversion probability distribution of every 5 years in 1984-2010

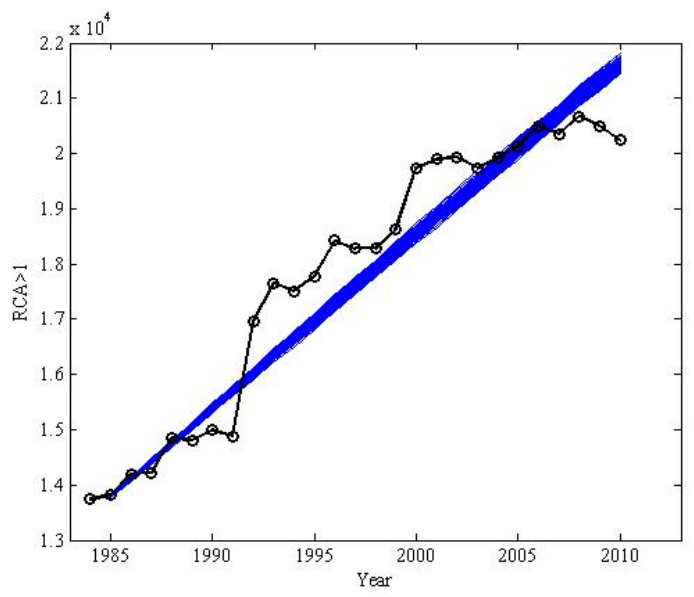

Fig. 2. The number of products with RCA $>1$ by simulation 100 times

This paper simulated the change of the number of products of RCA $>1$ by conversion probability distribution calculated from 1984 to 2010 . Fig. 2 is variation condition of the number of products with RCA $>1$ simulated 100 times. The black curve with hollow circular in fig. 2 says real change of the number of products with RCA $>1$ from 1984 to 2010 and the curve of the blue show the change of simulated values. We find that simulated values are close to the real number of products. Then we used the same method to analyze China export trade.

Fig. 3 is variation condition of China number of products with RCA $>1$ simulated 100 times. The black curve with hollow circular in fig. 3 says real change of China number of products with RCA $>1$ from 1984 to 2010 and the curve of the blue show the change of simulated and predicted values from 1984 to 2020 . We can easy find that the real number of export products of China is obviously less than the simulation number from fig.3, but the trend is consistent. Recent studies have found that China is "special" in exporting highly sophisticated products not comparable with its income level.[9] $\mathrm{Xu} \operatorname{Bin}(2010)[10]$ holds that product quality has not been fully considered in the measurement of economy complexity, which has caused an overestimation of the sophistication of China's exports. China number of products with RCA $>1$ is less than 300 in 2010, while the average of simulated values is more than 300 and it will get 340 in 2020, so we hold the opinion that China export economy complexity is overestimated and China's exports will be still rising. It is significant for China to make feasible trade policies and achieve trade structure upgrade efficiently.

The network shows clusters of products somewhat related to the classification introduced by Leamer[11]. Fig.4 is the product space of China by year 2020, and it is the simulation values. The yellow edges, blue edges, red edges and purple edges mean average proximity range is $0.4-0.5$, 
0.5-0.6, 0.6-0.7 and 0.7-0.8, respectively. The thicker the edge is, the closer two products are. The product space appears to have a core-periphery structure based on average proximity.

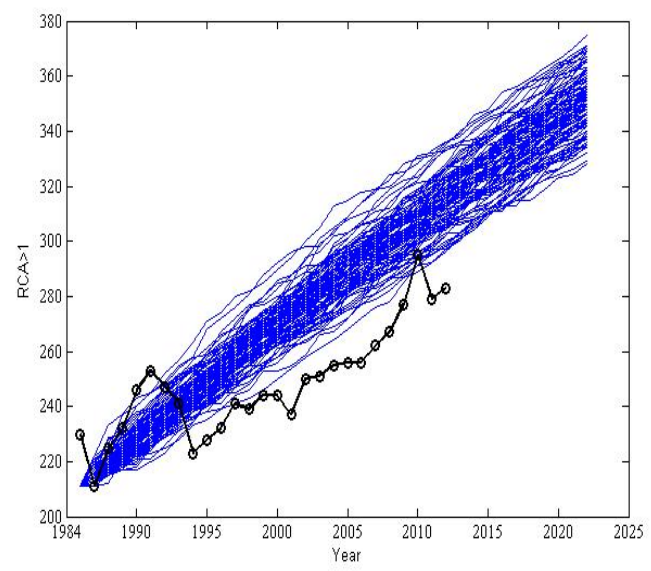

Fig. 3. China number of products with RCA $>1$ by simulation 100 times

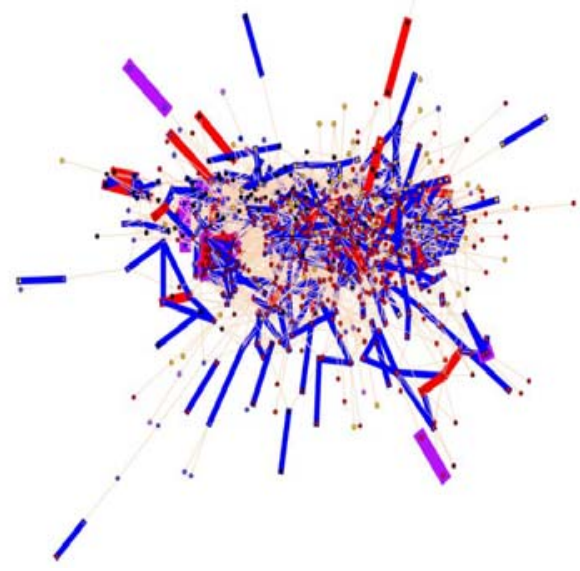

Fig. 4. The product space of China in 2020 and Leamer clusters

We also used the real export values to analyze the product space of China in 1985, and find that China product structure is focus on labor and capital intensive in 1985, and average proximity is almost between 0.5 and 0.7 , but the number of point is very few, that is to say, China kinds of export is poor. There are many points on fig. 4 which shows that China export become diversity gradually, as well as average proximity. The product space of China by year 2020 shows China export will be more diversity and complexity in the next decade.

\section{Conclusions}

This study introduced the concept of average proximity, calculated average conversion probability distribution, simulated the change condition of world and China number of products with RCA $>1$, and analyzed the relationship between average proximity and the amount of export trade of RCA $>1$ based on 1984-2010 international trade data.

We find that using the top three relevant products to calculate the average proximity can get appropriate analysis results. Average proximity can explain variation of number of products with RCA $>1$ well. At same time, we conclude that China export economy complexity is overestimation and China's exports will be still rising. Still, it is an important supplement for international trade and economy complexity field. It is significant for China to make feasible trade policies and achieve trade structure upgrade efficiently.

This paper only considers what countries/areas export without considering import. We also don't take the relationship of competition and restriction between countries into consideration, as well as export encouragement to high technological products and appropriate restrictions to low technological products production and export to raise their economy complexity. The simulation doesn't concern the product transformation direction in the next step. Maybe this is why the simulated curve is almost a straight line.

In the future work, we would bring the product transformation direction in the next step and consider export encouragement to high technological products and appropriate restrictions to low technological products. Considering the impact of competitive relationship between countries and the products produced and consumed domestically to product upgrade is also another research direction.

\section{Acknowledgements}

This research is sponsored by National Nature Science Foundation of China (No. 71125002), and all shortcoming remains to the author. 


\section{References}

[1] Balassa B. Trade liberalisation and "revealed" comparative advantage1[J]. The Manchester School, 1965, 33(2): 99-123.

[2] Hausmann, R., Hwang, J., \& Rodrik, D. What You Export Matters [J]. NBER Working Paper, 2005(11905).

[3] Hidalgo, Klinger, Barabási, R. Haussmann. The Product Space Conditions the Development of Nations[J]. Science, 2007(7), Vol317.

[4] Hausmann R, Klinger B. Structural transformation and patterns of comparative advantage in the product space[M]. Center for International Development at Harvard University, 2006.

[5] Lall S. The Technological Structure and Performance of Developing Country Manufactured Exports, 1985 - 98[J].Oxford DvlomnD, 2000, 28:337-369. DOI:10.1080/713688318.

[6] Lee J. Export specialization and economic growth around the world [J]. Economic Systems, 2011.

[7] Berg A, Ostry J D, Zettelmeyer J. What makes growth sustained? [J]. Journal of Development Economics, 2012, 98:149-166.

[8] Hausmann R., Hidalgo C.A., Bustos S., Coscia M., Simoes A, Yildirim M.A. 2013. The Atlas of Economic Complexity: Mapping Paths to Prosperity. The MIT Press, Cambridge, USA.

[9] nRodrik, Dani. What is so special about China's exports? China \& World Economy,2006, 14(5), $1-19$.

[10] Xu, Bin. The sophistication of exports: Is China special? China Economic Review 21, 2010, 482-493.

[11] E. Leamer, Sources of Comparative Advantage: Theory and Evidence, MIT Press,Cambridge MA, 1984. 